\title{
EDITORIAL
}

\section{PROMOCIÓN DE LA SALUD EN EL MEDIO ESCOLAR}

\section{Isabel García García.}

Subdirección General de Epidemiología, Promoción y Educación para la Salud. Dirección General de Salud Pública. Ministerio de Sanidad y Consumo.

Hemos querido dedicar este editorial a haccr algunas reflexiones sobre la importancia del desarrollo de la promoción de la salud y educación para la salud (EpS) en el ámbito escolar, dado que en este número aparecen una serie de trabajos sobre determinadas conductas relacionadas con la infancia y la adolescencia.

Nos parece, además, importante que en esta revista de salud pública se planteen estos temas, pues a menudo el personal de salud, principales lectores de la misma, centrado en el ámbito sanitario, se olvida del papel tan relevante que sobre la promoción de la salud y la EpS tienen otros sectores como es, en este caso, el educativo.

Sabemos que una parte importante de los problemas de salud que padece la sociedad actual son imputables al modo de vivir de las personas. Diversas enfermedades crónicas, las enfermedades cardiovasculares, diversos tipos de cáncer, el sida, las enfermedades de transmisión sexual o el estrés, tienen una relación directa con hábitos como los alimentarios, el tabaquismo, el alcoholismo y otros tipos de drogadicción, la falta de actividad física, la falta de habilidades personales para enfrentarse a situaciones vitales conflictivas o de presión social, etc. Muchas de estas conductas se adquieren en la infancia o en la adolescencia, implantándose de tal forma que tratar de cambiarlas posteriormente resulta difícil.
De ahí la importancia de ofrecer desde el primer momento la oportunidad de capacitar y educar a las personas favoreciendo y desarrollando actitudes y conductas saludables y dificultando las que son nocivas.

La adquisición de pautas de hábitos saludables ayuda al individuo a optar por estilos de vida en los que su salud sea un elemento valorado $\mathrm{y}$, por tanto, a evitar factores de riesgo que afecten de manera negativa a la calidad de vida.

Como muestran la mayoría de los trabajos publicados en el presente número, los primeros contactos y el inicio del consumo de sustancias como el alcohol y el tabaco, son bastante precoces entre los escolares.

Queremos recordar que los de la Promoción de la Salud y la EpS en la escuela, no son conceptos nuevos. Desde finales del siglo XIX tenemos ejemplos y modelos claros de la inquietud de los educadores en este campo, claro que aplicados a los problemas más relevantes de aquel momento. En esta etapa predominaba, por ejemplo, un modelo salubrista, preocupado sobre todo por las condiciones higiénicas personales y del medio escolar, y por el desarrollo de servicios de salud escolar. A partir de los años ochenta, predomina una concepción ecológica de la salud, que se preocupa por el desarrollo desde la infancia de comportamientos y estilos de vida saludables y por el desarrollo de entornos saludables, de ambientes gene- 
radores de salud, refiriéndose tanto al ambiente social como al físico; esto es, el individuo, la sociedad de pertenencia y el entorno físico interactuando de manera indisociable.

Hay que destacar el papel de la OMS en el apoyo de este modelo. Este organismo crea y pone en marcha en 1991 la Red Europea de Escuelas Promotoras de Salud, después de algunos años debatiendo y apoyando la inclusión de la EpS en el medio escolar. La Red es un proyecto tripartito de la Comisión Europea, el Consejo de Europa y la Oficina Regional de la OMS para Europa. España está adscrita a esta Red desde 1993, siendo el centro coordinador el Ministerio de Educación y Cultura con la cooperación del Ministerio de Sanidad y Consumo.

El éxito de una escuela promotora de salud depende, en parte, de la interacción con los otros elementos de la comunidad que la rodea. La familia, los vecinos y amigos, los lugares de reunión y de diversión, los servicios de salud, los medios de comunicación, forman una urdimbre social a la que no puede ser ajena el centro escolar.

Una escuela promotora de salud es aquella que proporciona unas condiciones óptimas para el desarrollo emocional, intelectual, físico y social de los alumnos. Se trata de promover, fomentar y permitir la adquisición de habilidades personales y sociales que conduzcan a crear valores y actitudes positivos hacia la salud, desde la propia capacidad de toma de decisiones personales, la participación y la igualdad, acorde siempre con el desarrollo intelectual, físico y mental del niño. El papel del profesorado es favorecer y permitir el desarrollo de estas habilidades.

Desde siempre se ha pensado, y no en vano, que la escuela es un lugar idóneo para la promoción de la salud. A la escuela concurre una amplia y variada población infantil y adolescente que pasa en ella muchas horas diariamente a lo largo de varios años.
Además es una población que está atravesando etapas cruciales para su desarrollo, en las que existe una gran receptividad y permeabilidad para el aprendizaje y asimilación de actitudes positivas hacia la salud y de hábitos saludables duraderos.

El objetivo que la EpS en la escuela debe proponerse alcanzar es el desarrollo de un creciente interés por la salud como un valor individual y social, que permita una adecuada calidad de vida a través del conocimiento y la comprensión de la relación directa entre las condiciones del medio, las socioculturales y las conductas individuales.

Las administraciones educativas y sanitarias, conscientes de la importancia de la promoción de la salud en el medio escolar, han abierto un amplio cauce de actuación para el desarrollo de la Educación para la Salud en la escuela, con las reformas llevadas a cabo en los últimos años (LOGSE y Ley General de Sanidad). La Ley General de Sanidad ${ }^{1}$ especifica la prioridad de la Promoción de la Salud y la EpS dentro del Sistema Nacional de Salud, así como la colaboración estrecha del personal de Atención Primaria de Salud con los sectores de población en el que los centros de salud están inmersos. La escuela es uno de ellos y son muchos los profesionales de la salud que están desarrollando proyectos de EpS conjuntamente con el profesorado y los padres y madres del alumnado, en la tarea de que los alumnos y alumnas adquieran y desarrollen hábitos saludables relacionados con la salud física, psíquica y social. La Ley de Ordenación General del Sistema Educativo (LOGSE) ${ }^{2}$, incluye la EpS como materia transversal en toda la educación infantil, primaria y secundaria obligatoria. La escuela tiene, pues, la responsabilidad de integrar la Eps en sus programas y esto significa sobre todo promocionar el valor salud entre el alumnado, de modo que se faciliten comportamientos sanos, la capacidad de decisión y elecciones personales desde la autonomía y el asentamiento de actitudes positivas duraderas para el cuidado de la salud. 
La EpS forma parte indiscutible del proceso educativo cuya función es formar de manera integral a los alumnos. Se trata tanto de transmitir conocimientos como de favorecer la adquisición de habilidades que ayuden a afrontar la realidad del modo más eficaz y, para lograr este objetivo, se requiere de la participación y el compromiso de todos.

La firma de un convenio de colaboración desde 1989 entre los Ministerios de Educación y Cultura y el de Sanidad y Consumo, es un claro exponente del interés y la preocupación de las administraciones por el desarrollo de la Promoción y EpS, lo que ha facilitado llevar a cabo acciones conjuntas en relación con el desarrollo de la EpS en el medio escolar.

$\mathrm{La}$ EpS en la escuela tiene que ser coherente con las necesidades manifiestas y potenciales de los alumnos, lo que significa que tienen que existir programas bien estructurados y con continuidad en el tiempo, para conseguir producir los comportamientos y actitudes que se pretenden promocionar. Las actuaciones puntuales y aisladas suelen ser poco productivas y, desde luego, nada satisfactorias ni para educadores ni para educandos.

Para acabar, queremos recordar en este espacio que la Declaración de los Derechos del Niño ${ }^{3,4}$ dice: el niño tiene derecho a recibir educación que le permita en condiciones de igualdad de oportunidades, desarrollar sus aptitudes y su juicio individual, su sentido de responsabilidad moral y social... Tendrá derecho a crecer y desarrollarse en buena salud... Los estados recono- cen el derecho del niño al disfrute del más alto nivel posible de salud y a servicios sanitarios, a conocer los principios básicos de la salud, la higiene y el saneamiento ambiental, las medidas de prevención de accidentes y a recibir apoyo en la aplicación de esos conocimientos... La educación de lo niños deberá ir encaminada a desarrollar la personalidad, las aptitudes y la capacidad mental y física del niño hasta el máximo de sus posibilidades.

Las escuelas tienen que responder a estos ideales de la Declaración, promoviendo la salud y fomentando el desarrollo de aptitudes para la vida, para la tolerancia y la solidaridad, la autoayuda y la cooperación. Conseguir que las escuelas sean lugares sanos y seguros donde sus pupilos, sin ningún tipo de discriminación e intolerancia, puedan vivir, aprender, jugar y trabajar, es una tarea de todos y desde luego al sector sanitario le corresponde una parte importante de la misma.

\section{BIBLIOGRAFÍA}

1. Boletín Oficial del Estado. Ley $14 / 86$ de 25 de abril General de Sanidad, (BOE 26/4/1986).

2. Boletín Oficial del Estado. Ley Orgánica 1/1990, de 3 de octubre, de Ordenación General del Sistema Educativo. (BOE 4/10/1990).

3. Asamblea General de las Naciones I Jnidas. Declaración de los Derechos del Niño. Organización de las Naciones Unidas; 20/10/1959.

4. Boletín Oficial del Estado. Real Decreto sobre Convención sobre los Derechos del Niño. (BOE núm $313,31 / 12 / 1990$ ). 